pachytene chromosomes could reveal morphological details not seen in more condensed chromosomes had practical value for mapping genes, but it also opened many questions about the meaning of these morphological features. (Of course, Drosophila polytene chromosomes present even more questions, but the way to visualize those chromosomes was yet to be discovered. If McClintock had worked on flies, might we have seen the wonderful polytene chromosomes years earlier?)

McClintock followed her corn chromosomes through their breakage and fusion antics, to a demonstration of the complexity of the nucleolus organizer, and then to the discovery of 'controlling elements'. Later, she used these chromosomes to study the origins and migrations of different races of corn. Comfort reconstructs the experiments, augmenting McClintock's difficult and minimalist published work with information from her field notes, memoranda and other papers. He presents a satisfying account of McClintock's discoveries of the dynamic nature of the genome. McClintock was always acutely aware that genetics needed to explain not only inheritance but also developmental biology and evolution. Comfort discusses her thinking on these subjects, pointing out that some of it was less than successful. Of course, even the greatest scientists sometimes bark up the wrong tree, but often just pointing out that the tree exists can influence later discoveries, even though that influence is not always recognized.

I heartily recommend this book to anyone interested in science or scientists. It will be welcomed even by those who have worked through McClintock's papers, because it fills in details omitted from her publications. For non-specialists, the science is clear enough to be accessible to anyone who has had a brief introduction to biology and genetics. The non-biologist has only to read around the experiments to become acquainted with a truly exceptional scientist.

Mary-Lou Pardue is in the Department of Biology, Massachusetts Institute of Technology, 77 Massachusetts Avenue, Cambridge, Massachusetts 02139-4307, USA

\section{Born in difficult} \section{times}

Per Una Storia del Consiglio Nazionale delle Ricerche (2 vols) edited by R. Simili \& G. Paoloni Editori Laterza: 2001

Vol. I 682 pp. IL70,000, 36.15 euros

Vol. II 688 pp. IL70,000, 36.15 euros

\section{Giorgio G. C. Palumbo}

The mathematician Vito Volterra, now best known for the solutions to integral equations that bear his name, played an impor-
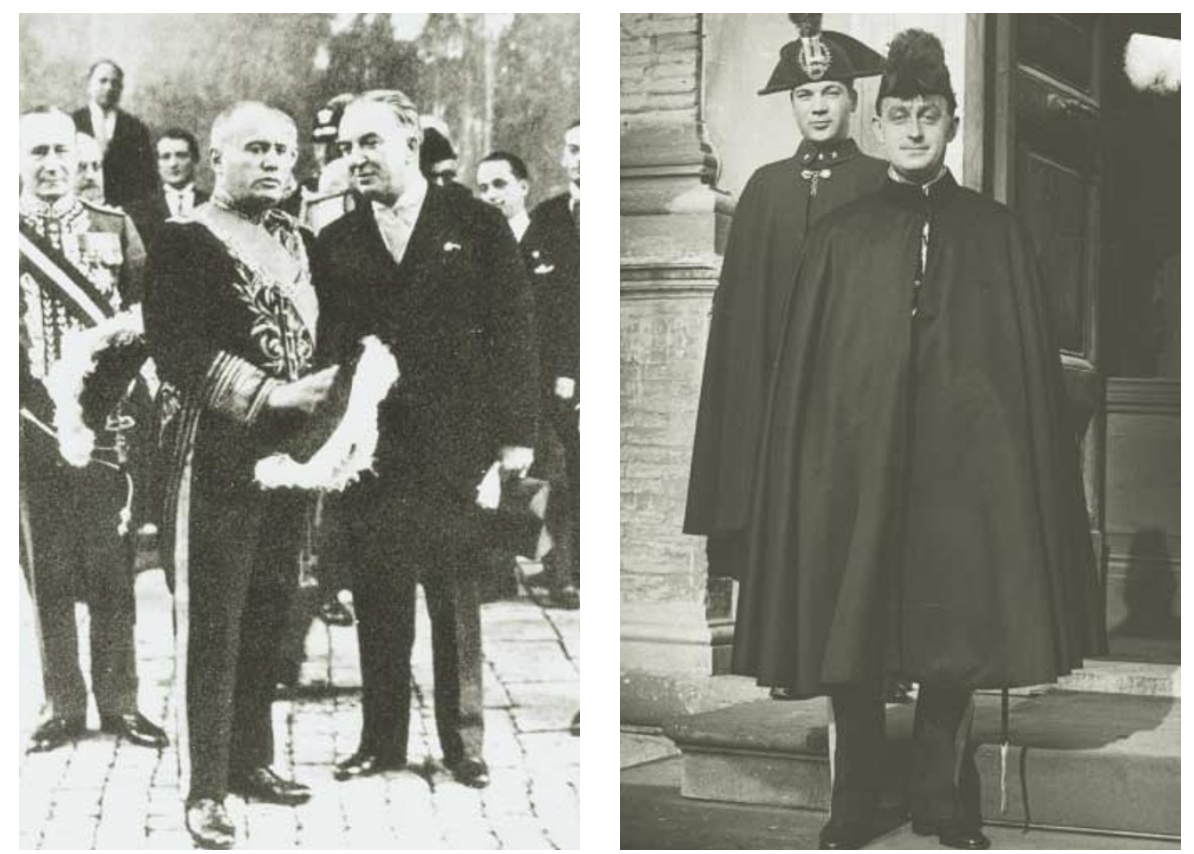

Italian Nobel winners: left, Marconi (left), who wanted to transform the CNR into a great laboratory of war and peace, was admired by Mussolini (centre); right, Fermi's early work was supported by the CNR.

tant political role in Italian science during the early days of Mussolini's dictatorship. Respected at home and well-known abroad, Volterra did all he could to put Italian science on an equal footing with its international counterparts: he was instrumental in Italy's joining the principal international scientific unions (such as the International Astronomical Union and the International Union of Pure and Applied Physics).

So it was appropriate that, on 18 November 1923, Volterra became the founding father of the CNR, Italy's national research council. His dream was to create research institutes that could compete with the best of Western science. But Volterra was a Jew and was deposed as CNR president in 1930. After his refusal in November 1931 to swear loyalty to the Fascist government, he was forced to step down from all his academic responsibilities - as professor of theoretical physics at the University of Rome and as president of the Accademia dei Lincei. In December 1934, in a letter to his friend George Hale, then president of the US National Research Council, Volterra wrote: "If you no longer see my name in the list of members of the Accademia dei Lincei, do not assume I am dead." Sadly, the regime lasted longer than he did, and Volterra died in obscurity in 1940.

Such were the times in which the CNR was born. After almost 80 years of complex, often tormented history, the institution is now undergoing profound reform. So the publication of these two volumes (in Italian), in which 27 historians make a welldocumented attempt to describe the intricacies of the CNR's evolution, is particularly well-timed.
The first volume covers the period from the CNR's foundation to the years of the Second World War (1939-45). Volterra's successor was the famous physicist Guglielmo Marconi, Nobel prizewinner and national hero, and much admired by Mussolini. Marconi promptly encouraged

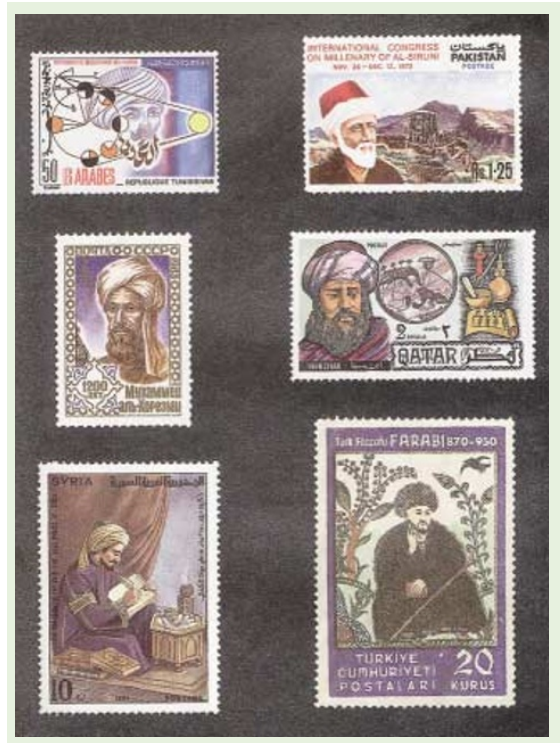

Mathematical philately

A page of stamps featuring early Islamic mathematicians, from Stamping through Mathematics by Richard J. Wilson (Springer-Verlag, \$29.95), an annotated collection of mathematical stamps. 
council members to transform the CNR into "a great laboratory of war and peace". Soon after taking office, however, Marconi moved on to even more spectacular scientific adventures, leaving the CNR in the hands of the vice-president, a fascist bureaucrat. From 1937, and during the war, General Pietro Badoglio, a powerful military and political figure, became CNR president, with a mandate to promote war-orientated science and technology.

It is interesting that the Italian scientific community mostly ignored Badoglio's loud propaganda, and very little science for war was developed - unlike the situations in Britain and Germany. Mussolini did not trust university professors much, despising their inclination to pursue fundamental research and ignore industrial applications. With these unresolved contradictions, the CNR entered the war period.

This early story is documented in detail with fascinating extracts from correspondence between scientists, politicians and members of the CNR council. When read decades later, comments, opinions and gossip reveal much more about the political planning behind the scene than do the official facts - as well as revealing the personalities of the correspondents, all outstanding figures in Italian science.

For example, in 1936, Giulio Cesare Trabacchi, director of the Istituto Superiore di Sanitá (National Institute of Health), lost 10,000 lire (a significant amount of money at the time) from his CNR grant after a clerk mistakenly assigned it to Enrico Fermi, who was then still working in Italy. Responding to a letter in which it was suggested that the sum could be returned to him and stripped from Fermi's grant the following year, he replied: "I have closely followed Fermi and his school's work and I well know how desperately meagre are the resources available to them. I would accept the proposition you suggest only if I could be sure my work could be compared to Fermi's and collaborators': I know this can't be done ... I therefore will continue with the ordinary grant I so far had access to." It is now clear why Trabacchi is the only person Fermi thanked in his Nobel lecture after winning the prize for physics in 1938.

The second of these volumes spans the period from the post-war republic to the present. It is inevitably written almost as a chronicle, and touches on delicate points concerning people who are still alive and active in their fields. The change in style between the volumes prompts a general question: how will future historians assess our present era of non-archived web documents, e-mails and all-too-frequent mobile phone calls? Records of who was where at what time, and of what they were thinking or working on, and with whom - the
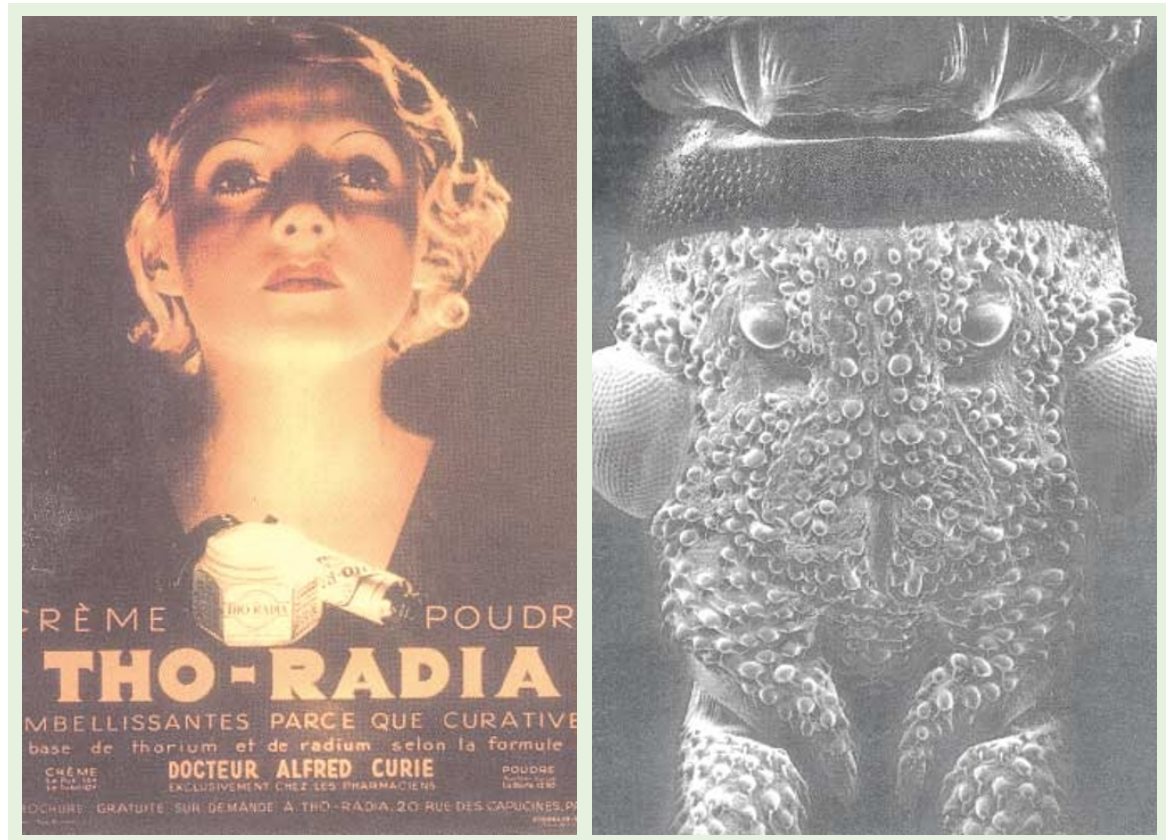

\section{Beauty and the beast}

Images from the Dictionnaire culturel des sciences (Editions du Regard/Editions du Seuil, 2001, FF495, in French), an eclectic mix of a thousand short articles on science and its influences on and from art, cinema, literature, politics and religion. From ADN (DNA to English speakers) to Zoroastre, this is a book to delight and provoke, in which Niels Bohr keeps company with James Bond and William Blake. 'Beauty' (left) is an advertisement for a beauty product that purported to use radium; 'beast' (right) is an artist's impression of an electron micrograph of a bed-bug, entitled 'Doctor Honoris Causa'. human aspects of history — are all bound to be lost.

The post-war years have seen the CNR's scientists promoting European collaborations (through CERN - the European Organization for Nuclear Research - and ESRO, the latter of which metamorphosed into the European Space Agency and the European Southern Observatory, among other agencies), activating connections with the United States, particularly with colleagues who had fled the fascist regime, and starting technological projects, such as a programme for science in space. However, in the account, little emerges of the intricacies of the political scene. No doubt it is too early - the books, in fact, are presented as a contribution for a history of the CNR to be written in the future.

After the war, scientific leadership resided in the universities, and most CNR laboratory directors were university professors; CNR laboratories and research centres were physically located in university buildings. In the late 1960s, however, a significant change occurred with the creation of independent institutes; CNR directors are now mostly staff members of these facilities. The price of independence from academia has been high: scientific isolation and almost no access to graduate students and postdocs.
Since the 1960s, the CNR has had a peculiar policy of recruiting in 'quantum' jumps. A few months ago, for instance, about one thousand people became staff members all at once after about ten years of 'hanging around'. But in spite of all the clumsy planning, a good deal of Italy's basic research is done within the CNR or in collaboration with CNR staff.

Present CNR leaders should take a close look at these two volumes. The political approach to science in Italy is described well, and its somewhat baroque design emerges clearly. All evolutionary efforts seem to have been in vain. For example, the most outstanding and constant feature of the CNR is its endemic lack of funds. The recurrent cry of presidents, of whatever political faith, has been that Italy's investment in science and research has been at best about half that of other developed countries, and more often only a third. As a rule, CNR scientists receive salaries, offices and lab space and not much else; research grants must be sought elsewhere. Perhaps the current restructuring will give the CNR the opportunity to finally realize Volterra's dream.

Giorgio G. C. Palumbo is in the Astronomy Department, University of Bologna, Via Ranzani 1, 40127 Bologna, Italy. 